 \\ Journal of Transportation and Logistics \\ 4 (2), 2019
}

Received: December 01, 2019 Accepted: December 31, 2019

http://dx.doi.org/10.26650/JTL.2019.04.02.03

Research Article

\section{Metaheuristic Solution Approach for Two-Dimensional Palette Placement Problem}

\author{
Irem Ünal | Industrial Engineering, Faculty Of Engineering, Marmara University, Turkey, iremu96@gmail.com \\ Hakan Görgün | Industrial Engineering, Faculty Of Engineering, Marmara University, Turkey, hakan.gorgun@intecon.com.tr \\ Serol Bulkan | Industrial Engineering, Faculty Of Engineering, Marmara University, Turkey, sbulkan@marmara.edu.tr
}

\section{Keywords: \\ Pallet Loading \\ Problem (PLP), \\ Genetic Algorithm, \\ Two-Dimentional \\ Loading}

\section{ABSTRACT}

This study emphasis on the type of pallet loading problem (PLP), which is closely associated with logistic management. In the study, which is made specifically for the distributor pallet loading problem, the dimensions of width, length and height of the products are considered to be the same, and the study, which is based on distributor pallet loading problem, has been conducted in a way that the dimensions of products will be reduced to the $2 \mathrm{D}$ pallet loading problem without loading a $3 \mathrm{D}$ pallet. The research concentrates on the constraint of loading different customers' pallets so as not to mix their products during transportation and as the problem will be examined in 2-dimensions, instinctively objects are only allowed to be rotated in 2-dimensions. A Genetic Algorithm (GA) has been developed for the problem solution and this algorithm has been presented to give good results.

\section{Iki Boyutlu Palet Yerleştirme Problemi İ̧in Metasezgisel Çözüm Yaklaşımı}

\section{Öz}

Anahtar Sözcükler :

Bu çalışma, lojistik yönetimini yakından ilgilendiren palet yükleme problem (PYP) tipi üzerine yoğunlaşan bir çalışmadır. Dağıtıcı palet yükleme problemi özelinde yapılan bu çalışmada ürünlerin en, boy ve yükseklik ölçülerinden bir boyutu aynı olacak şekilde kabul edilip çalışma 3 boyutlu palet yüklemeden 2 boyutlu palet

Palet yükleme problemi (PYP), yükleme problemine indirgenecek şekilde incelenmiştir. Öyle ki, farklı müşterilerin ürünlerini taşıma sırasında karıştırmayacak şekilde paletlere yüklenmesi kısıtı üzerine yoğunlaşır ve problem 2-boyutta inceleneceği için de Genetik Algoritma, 2- doğal olarak nesnelerin sadece 2-boyutta döndürülmesine izin verilmiştir.

Boyutlu Yükleme Problem çözümü için bir Genetik Algoritma (GA) geliştirilmiş ve geliştirilen bu algoritmanın iyi sonuç verdiği gösterilmiştir.

Cite this article as

Ünal, i., Görgün, H., \& Bulkan, S. (2019). İki Boyutlu Palet Yerleştirme Problemi İçin Metasezgisel Çözüm Yaklaşımı. Journal of Transportation and Logistics, 4(2), 79-90. doi: 10.26650/JTL.2019.04.02.03 


\section{Giriş}

Günümüzde firmalar ürün geliştirme ve böylece pazardan daha fazla getiri elde edebilmek için her türlü araştırma ve geliştirme faaliyetlerine ağılık vermektedir. Burada amaç, anaparayı ürüne katma değer yaratacak bir şekilde kullanarak müşterinin ihtiyaçlarını karşılamak ve küresel pazarda diğer firmalarla rekabet edebilmeye devam etmektir. Durum böyle olunca katma değer yaratmayan her türlü gider aslında firmalar için bir yüktür.

Bu bakış açısı ile lojistik faaliyetlerini ele aldığımızda karşılaşılan tablo istenmeyen giderlerle doludur. Her türlü depolama, yerleştirme ve taşıma maliyetleri en küçüklenmesi gereken kalemlerdir. (Song vd., 2019)

Bu çalışma, lojistik faaliyetlerinin bir kolu olan palet yükleme problemlerine (PYP) odaklanmaktadır. PYP, adından da anlaşılabileceği üzere farklı ve/veya aynı en, boy ve yükseklik ebatlarına sahip nesnelerin belirlenen amaç fonksiyonunu en büyükleyecek/küçükleyecek şekilde kapasitesi belli paletlere yüklemeyi konu alan bir optimizasyon problem tipidir. PYP'ler temelde üretici palet yükleme problemi ve dağıtıcı palet yükleme problemi olacak şekilde ikiye ayrılır. Buradaki temel farklııık taşınacak nesnelerden kaynaklanır. Üretici palet yükleme probleminde yüklenecek nesnelerin genellikle en, boy ve yükseklikleri kendi içlerinde aynıdır ve amaç, bir palette taşınacak olan ürünlerin sayısını eniyilemektir. Bunun tersi olarak dağıtıcı palet yükleme probleminde yüklenecek nesnelerin en, boy ve yükseklikleri birbirinden farklıdır ve amaç, kullanılacak palet sayısını en küçüklemektir. (Scheithauer, G., 2018) Bu çalışma, dağıtıcı palet yükleme problem tipine yoğunlaşmaktadır.

Yüklenecek nesnelerin ebatlarındaki farklılık, beraberinde göz önünde bulundurulması gereken diğer faktörleri de getirir. En temelde, bu nesnelerin kütle ve hacim değerlindeki farklılıktan dolayı yoğunlukları da farklı olabileceği için bu nesneler yerleştirilirken kırılganlıkları ve/veya yapılarının bozulabileceği olasılığını da beraberinde getirir.

Anlaşılabileceği üzere, PYP tipindeki problemlerde, yüklemesi yapılacak nesneler ve çevresel faktörlerden kaynaklanan belirli değişkenler ve kısıtlar devreye girer. Bu çalışma aşağıda sıralanan kısıtları göz önüne alacaktır:

2-Boyutlu Döndürme Kısıtı: Yüklemesi yapılacak nesnelerin 3-boyuttan 2-boyuta indirgenmesinden dolayı sadece 2-boyutta döndürülebileceğini ifade eden kısıttır. Bu durumda belirlenen nesneler ya verilen (dik) şekilde ya da yan yatırılarak yerleştirilmesine izin verilecektir.

Bağlantılı Nesneler Kısıtı: Bu kısıt, bir palette sadece tek bir müşteriye ait ürünlerin taşınmasına izin verir. Farklı müşterilerin siparişlerinin aynı palete yüklenmesinin önüne geçilerek yükleme ve boşaltma sırasında zamandan tasarruf edilmesi hedeflenir. (Terno et al., 2000)

PYP'leri polinomial zamanda en iyi çözüme ulaştırmak mümkün olmadığı için NP-Hard sınıfına girer. (Ahn et al. 2015) Bu sebeple belirlenen problemi çözmek için literatürde geliştirilen çeşitli sezgisel metotlara rastlamak mümkündür. Bu çalışmada, daha iyi çözüm elde etmek için Genetik Algoritmalardan yararlanılmıştır. Böylece daha kısa 
zamanda olurlu bölgedeki optimal çözüme en yakın değerin elde edilmesi hedeflenmiştir.

\section{Literatür Araştırması}

Dowsland (1987a) çalışmasında bir Palet Optimizasyon Sistemi (POSY) önererek bu sistemle paletlere yerleştirilen kutuların optimum sonuç verdiğini ve çözümün en fazla 5 dakika sürdüğünü göstermiştir. Dowsland (1987b)'deki çalışmasında ise Dowsland (1987a)'da belirttiği sistemde yer alan bazı zorlukların üzerine yoğunlaşmıştır. Bu zorlukların problemlerin çözüm sürelerinden kaynaklandığını belirterek (5 dakika olarak belirlenen limit değerin aşılması durumu) POSY'den bağımsız bir yaklaşım ile bu soruna çözüm getirmiştir.

Chen vd. (1991) malzeme taşıma sistemlerinin tasarımı üzerine yoğunlaşarak iki tabanlı tam sayılı formülasyon geliştirmişlerdir. Ele alınan matematiksel model çoklu paletleri ve malzemelerin paletlere uyumunu kapsar. Problem aynı zamanda kutuların ölçülerinin tam sayı olması gerekmediği durumunu da göz önüne alır.

Tarnowski vd. (1994) 2-boyutlu giyotin kesme stok problemleri için polinomial zamanlı bir algoritma üzerine çalışmıştır. Algoritma, ilk problemin 3 alt probleme bölünmesi üzerine kuruludur.

Nelißen (1995) çalışmasında 1995 yılına dek literatürde bulunan sezgisel algoritmaları önerdiği yeni üst sınır metodu ile optimal sonuç verip vermediklerini doğrulamıştır. Metot, bazı yapısal kısıtlardan temel almış ve 28 problem hariç rastgele üretilen 20.000 problemi doğru bir şekilde çözüme ulaştırmıştır.

Bischoff vd. (1995) dağıtıcı palet yükleme problemleri üzerine çalışmışlardır. Çalışmanın sonucunda yeni bir sezgisel algoritma öne sürülerek etkin bir yükleme yapılmasını sağlamanın yanı sıra doğal dengenin de kurulmasına olanak sağlamıştır.

Bhattacharya vd. (1998) çalışmalarında derinlik öncelikli strateji kullanarak hızlı ve kesin bir algoritma sunmuştur. Arama ağacının boyutunu düşürmek için yeni bir konsept geliştirilmiştir. Kullanılan baskın budama kuralı, hazırda bulunan hafızayı kullandığından dolayı büyük problemler için daha fazla hafızanın ulaşılabilir olması gerekir. Böylece daha etkili budama yapılabilir.

Terno vd. (2000) dağıtıcı palet yükleme problemleri üzerinde durmuş ve sezgisel bir algoritma geliştirmiştir. Çalışma temelde, 3-boyutlu çözüm yönteminin 2-boyutlu optimum yükleme modelinin katman bazında yüklenmesi stratejisi ile kullanılmasını içermektedir.

Gencer (2000), çalışmasında Chen, Sarin ve Ram'in karışık tam sayılı modeline ek bir kısıt önererekmiştir. Böylelikle bu karışık tam sayılı modelin çözümünde ortaya çıkan kutu - palet atama uyuşmazlıklarına çözüm önerisi geliştirmiş ve böylelikle de modelin gelişmesine katkı sağlamıştır.

Young-Gun ve Kang (2001) 2-boyutlu palet yükleme konusuna eğilerek bu problem tipi için sezgisel bir algoritma geliştirmiştir. Çalışmalarındaki basit amaç fonksiyonu daha az komplike ve daha ile etkili bir şekilde bu problemi çözebilmektir. Ek olarak, sezgisel algoritmayı alt-algoritma olarak kullanan başka bir yöntemden daha bahsedilmiştir. Bu yeni yöntem ise 5-blok yapısına sahip kompleks karmaşık 
çözümlerin hızlıca bulunmasına olanak sağlarsağlamaktadır. Araştırma sonuçlarında görüldüğü üzere bu yeni algoritma 6800'ü aşan kutu sayısına sahip PYP'lerde başarılı sonuç vermektedir.

Letchford ve Amaral (2001)'ın literatürdeki üst sınırların analizi üzerine yaptığı çalışmalar sonucunda bu sınırların pratikteki sıralaması çıkarılmış ve bunlardan iki tanesinin diğerlerini domine ettiği fark edilmiştir. Bunlar biri Nelissen'in sınırı, diğeri de doğrusal programlama rahatlatmasından elde edilen formülasyondur.

Birgin vd. (2005), Lins vd. (2003)'nin çalışmasını geliştirecek bir öneride bulunmuştur. Lins vd. (2003) çalışmalarında öne sürdükleri yaklaşımda, küçük dikdörtgen parçaları daha büyük dikdörtgen ve L-şeklindeki parçalara yerleştirecek geri dönüşümlü bir algoritma üzerinde durmuştur. Öne sürdükleriÖnerdikleri L-Yaklaşımında amaç, zorlu palet yükleme problemlerini çözmektir. Tahminlerine göre bu yaklaşım, ve küçük dikdörtgen parçaların daha büyük dikdörtgen parçaların üzerine optimal bir şekilde yüklenmesini sağlarsağlamaktadır. L-şeklinde parçalar içeren kesme ve paketleme problemleri için de oldukça kullanışlı olacağı öngörülmüştür. Birgin vd. (2005) ise bu yaklaşımın işleyiş süresindeki dezavantajı ele almıştır. Farklı bir veri yapısı kullanarak işleyiş süresini kabul edilebilecek seviyeye indirmiştir. Bu indirgeme, yaklaşımın uygulamadaki kullanılabilirliğini arttırmasına rağmen hafıza gereksinimini de arttırırarttırmaktadır.

Alvarez-Valdes vd. (2005) PYP'ler için dal-kesme algoritması önermiş, bunu yaparken de Beasley tarafından önerilen iki bileşenli formulasyondan yararlanmıştır. Beasley (1985)'nin kesme problemleri için sunduğu bu tanımlamaya ek olarak yeni kısıtlar ve değişken indirgemek için yeni prosedürler önerilmiştir. Bunlara ek olarak AlvarezValdes vd. (2005) kullandıkları problem tipinin özel yapısından yararlanarak etkili ayırma yöntemleri de geliştirmiştir.

Chan vd. (2006) palet seçimi ve yüklemesi konusunun alt başlığı olarak hava yollu taşımacılık için maliyet optimizasyonu amacıyla karar destek sistemi üzerine odaklanmıştır. Çalışmanın literatüre katkısı, hava kargosu için kullanılan farkı ı̧ekil ve boyutlardaki paletlerin 3-boyutlu yükleme konusuna farklı bir bakış açısı geliştirmesidir. Bunun sonucunda geliştirilen sistem, söz konusu paletler üzerinde başarıyla uygulanmış ve \%90'ın üzerinde hacim kullanımına ulaşılmıştır.

Martins ve Dell (2008) çalışmalarında yeni sınırlar, sezgiseller ve kesin algoritma geliştirmiştir. Önerilen G5-sezgiseli ele alınan problem sınıfının yaklaşık \%99,7'sini optimum olarak, kalan \% 0,3'lük kısmını ise en iyi çözümden sadece bir kutu farkı olacak şekilde sonucu bulmuştur.

Lau vd. (2009) palet yüklemesi konusuna kar eniyilemesi amacıyla yaklaşmıştır. Sezgisel ve genetik algoritmalardan yararlanılan bu hibrid çalışma, doğrusal olmayan tam sayılı programlama problemleri içindir ve benzetimli tavlama (simulated annealing), tabu search ve doğrusal olmayan tam sayılı problem tabanlı metotlardan ve dal-sınır algoritmalarından daha karlı olduğu görülmüştür.

Schuster vd. (2010) dağıtıcı palet yükleme problemi için farklı bir algoritma geliştirmişlerdir. Var olan algoritmaların aksine bu çalışmada yığının hacminin yanı sıra dengesini de eniyilemiştir. Çalışmanın PYP'leri ilgilendiren bölümünde paletlere yükleme yapılırken farklı müşterilerin ürünlerinin olabildiğince az aynı paletlere 
yüklenmesine gayret edilmiştir. Genel duruma bakıldığında öne sürülen model küçük ölçekli problemleri optimum çözebilmektedir.

Ahn vd. (2015a) bir palete yüklenecek olan kutu sayısını eniyileyecek PYP'ler için yeni bir dal-sınır algoritması önermiş, bu algoritma içerisinde de olurlu çözümü kontrol eden bir alt algoritma tanımlamıştır. Söz konusu çözüm yöntemi, bir problem hariç olmak üzere alan oranı sınırı 101'den küçük olan 3 milyon problemi 1 dakikadan az sürede çözerek literatürdeki diğer algoritmalardan üstünlüğünü kanıtlamıştır.

Ahn vd. (2015b) geometrik özellikleri göz önüne alındığında oldukça kullanışlı olan merdiven yapısında düzen üreten bir algoritma geliştirmiştir.

Song vd. (2019) hem araç rotalaması hem de ürünlerin araca yüklenmesi problemlerini gerçek hayattaki uygulama alanlarında inceleyerek oldukça geniş bir çalışmaya imza atmışlardır. Bu çok amaçlı optimizasyon probleminde üç farklı amaç fonksiyonu bulunmaktadır. Bunlar; toplam seyahat mesafesinin, kullanılan rota sayısının ve aynı palete yüklenen ürünlerin karışmasının en küçüklemesi olacak şekilde düzenlenmiştir. Belirlenen problem, karmaşık sayılı doğrusal programlama ile modellenmiştir.

Kır ve Yazgan (2019) çalışmasında literatürde bulunan çalışmalarda öne sürülen problemlerin yanı sıra yeni kısıtlar ile de çalışarak konuya yeni bir yaklaşım geliştirmiştir. Karışık tam sayılı programlama ile modellemesi yapılan çalışma hibrid genetik algoritma ile iki adımda çözülmüştür.

\section{Kullanılan Algoritmalar}

Bu çalışmada öne sürülen meta-sezgisel çözüm yaklaşımında Genetik Algoritma (GA)'lardan yararlanılmıştır. Sunduğu birçok avantaj sayesinde optimizasyon problemlerinin çözümünde literatürde sıkça karşılaşılan Genetik Algoritmaların, palet yükleme problemlerinde de sıkça kullanıldığı görülmektedir.

Darwin'in Evrim Teorisinde ortaya koyduğu doğal seçilimden ilham alan bu algoritma türü, genetik ve evrim konularının yöneylem araştırmaları kapsamında kullanılması ile ortaya çıkmıştır. GA'lar herhangi bir ön koşul sağlaması gerekmeden her türlü eniyileme probleminde kullanılabilir. Bu sebeple polinomial zamanda çözülemeyen problemlerin çözümü için sıkça kullanılmaktadır.

Uygulama, her basamakta olası bir çözüm bulmak yerine olası çözümlerden oluşan kümeler ile çalışmak mantığına dayanır. Bu çözüm kümesine "popülasyon" veya "nesil" denir. Her popülasyon kromozomlardan oluşur. Bunlar her bir olası çözümü temsil eder. Kromozomlar ise genlerden oluşur. Bu genler ise çözümlerin tanımlanması için gerekli bilgiyi taşır. (Mitchell, 1998)

Biyolojide olduğu gibi, yeni nesillerin üretilmesi çaprazlama ve mutasyondan sayesinde gerçekleşir. Algoritmada seçilen kromozom ikililerinin ("ebeveyn") çaprazlanması ve sonrasında belirlenen kriterler kapsamında yeni oluşan kromozomlarda ("çocuklar") mutasyonlar gerçekleştirilerek yeni nesiller oluşturulur ve en uygun yeni kromozomlardan bir sonraki nesil oluşturulur, sonrasında algoritma başa döner. Bu döngü durdurma kriterine kadar devam eder. (Sivanandam \& Deepa, 2008) 
Bu çalışmada, öncelikle Genetik Algoritma kullanılarak her bir problem için en iyi çözüm kromozomu elde edilmiştir. Sonrasında bu kromozomlardan elde edilen çözümden yola çıkarak En lyi Dikdörtgen Alan Uyumu (Maksimum Rectangle Best Area Fit (MRBAF)) algoritması ile ürünlerin paletlere yüklenmesi sağlanmıştır. Yüklemenin ardından ise amaç fonksiyonu hesaplanmıştır. (Jylänki, 2010)

\section{Geliştirilen Çözüm Metodu}

Bu çalışmada tanımlanan problem bir 2-boyutlu dağıtıcı palet yükleme problemidir. Bu kısasa göre farklı ebatlardaki ürünler paletlere doluluk oranını eniyileyecek şekilde yüklemektir. Çalışmada kullanılan palet boyutları $100 \mathrm{~cm}$ x $120 \mathrm{~cm}$ olarak belirlenmiştir. Ürünlerin boyutları ise uniform dağıım ile belirlenmiştir. Genişlik ve uzunluk ölçüleri, sırasıyla "20, 25, 30, 35" cm ve "25, 30, 35, 40, 45, 50" cm kümelerinden seçilmiştir. Ürünlerin yükseklik değerleri ise hepsi için $25 \mathrm{~cm}$ alınıp sabitlenerek problem 2-boyutta incelenmiştir.

Her ürün için bir kırılganlık indisi belirlenerek yüklemeler bu indise göre yapılmıştır. Bu indis değerleri " 0 ”, “1", “2" veya "3" olabilir, bu indisler ürünlere aşağıdaki olasılık değerlerine göre rastgele bir biçimde atanmıştır.

$P\left({ }^{\prime \prime} O^{\prime \prime}\right)=0.05$

$P\left({ }^{\prime \prime} 1 "\right)=0.1$

$P\left({ }^{\prime \prime} 2^{\prime \prime}\right)=0.25$

$P\left({ }^{\prime \prime} 3^{\prime \prime}\right)=0.6$

Burada, " $O$ " indisi en kırılgan ürün grubu içindir ve yükleme sırasında palette en üst sırada yer almalıdır. Tersi olacak şekilde " 3 " indisi ise en az kırılgan ürün grubudur ve yükleme sırasında paletin en altında yer alabilir.

Kırılganlık"0"> Kırılganlık"1"> Kırılganlık"2"> Kırılganlık"3"

2-boyutta çalışılan bu problemde yine ürünler 2-boyutta döndürülerek paletlere yerleştirilebilir.

Diğer bir önemli nokta ise problemde farklı müşterilere ait ürünlerin bulunmasıdır. Buna göre farklı müşterilerin ürünleri aynı palete yüklenmemelidir. Müşteri sayısı ise toplam ürün sayısının üçe bölünmesi ile belirlenmiştir. 
Önerilen çözüm yaklaşımı için kullanılan algoritmanın pseudo kodu aşağıda verilmiştir.

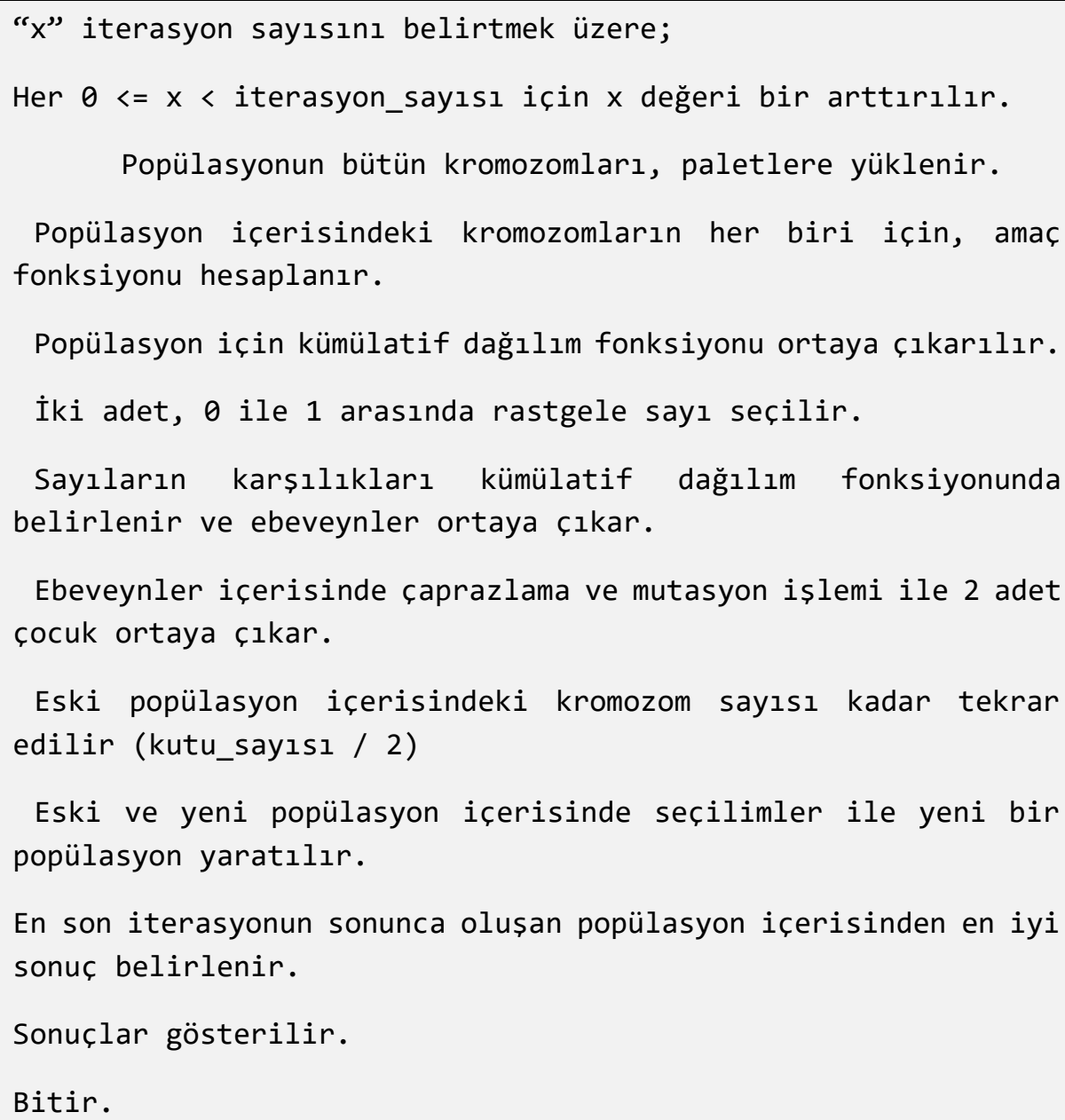

Algoritmanın aynı zamanda akış şeması Şekil 1'de verilmiştir. 


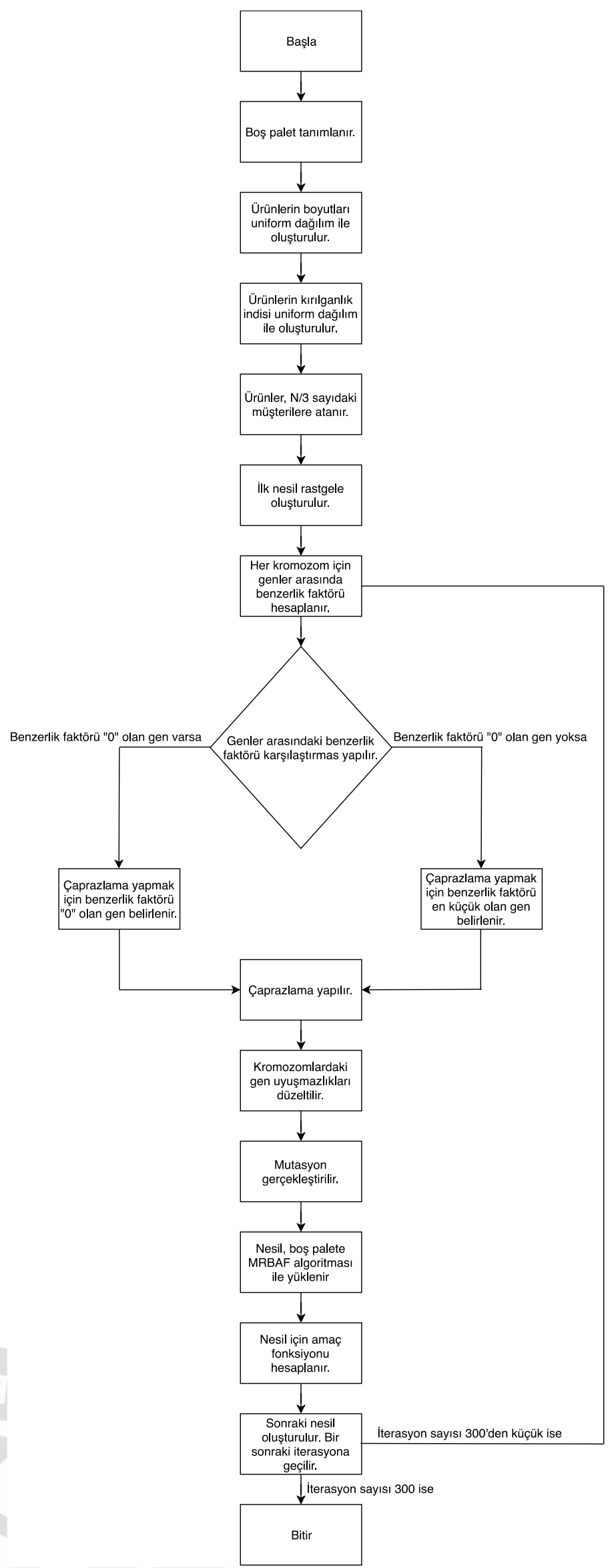

Şekil 1: Algoritmanın Akış Şeması 
Algoritma, paletin doluluk oranını eniyilemeyi amaçlar. Algoritmanın amaç fonksiyonu;

$Z=\sum_{i=0}^{M}\left(2^{M-1-i} \times(\right.$ paletteki toplam kutu hacmi / paletin toplam hacmí) $)$
$-2^{(\text {Paletten Taşan Aym Palette Olmast Gereken Kutu Sayısi }-N)}$

Burada parametreler;
M: Olası palet sayısı
$\mathrm{N}$ : Ürün sayısı
i: Palet için indis

Bu fonksiyonu

" $\left(2^{M-1-i} \times(\text { paletteki toplam kutu hacmi / paletin toplam hacmi })\right)^{\text {" }}$

n kısmı, ürünlerin mümkün olduğu kadar ilk paletlere yüklenmesini zorlar. Böylece paletlerin doluluk oranı maksimize edilmiş olur.

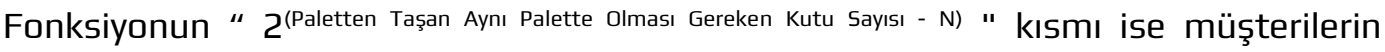
ürünlerinin farklı paletlere yüklenmesi durumunu engellemeye çalışır. Böylece paletlerin doluluk oranının azalmasını engeller.

Önerilen meta-sezgisel çözüm yaklaşımı 80, 100 ve 120 adet kutudan oluşan deney setleri ile test edilmiştir. Test sonuçları Tablo 1'de verilmiştir.

Tablo 1: Test Sonuçları

\begin{tabular}{|c|c|c|c|c|c|c|}
\hline \multirow{2}{*}{$\begin{array}{l}\text { Kutu } \\
\text { Sayısı }\end{array}$} & \multirow[t]{2}{*}{ Problem No } & \multicolumn{2}{|c|}{ Kullanılan Palet Sayısı } & \multicolumn{3}{|c|}{ Amaç Fonksiyonu Değeri } \\
\hline & & Minimum & Maksimum & Minimum Değer & Maksimum Değer & Ortalama Değer \\
\hline \multirow[t]{5}{*}{80} & 1 & 3 & 3 & 5.56 & 11.34 & 6.76 \\
\hline & 2 & 3 & 3 & 5.56 & 11.31 & 6.74 \\
\hline & 3 & 3 & 3 & 5.54 & 5.71 & 5.61 \\
\hline & 4 & 3 & 3 & 5.54 & 5.74 & 5.63 \\
\hline & 5 & 3 & 3 & 5.53 & 5.71 & 5.61 \\
\hline \multirow[t]{5}{*}{100} & 1 & 4 & 4 & 11.89 & 12.16 & 12.02 \\
\hline & 2 & 3 & 4 & 11.98 & 12.25 & 12.11 \\
\hline & 3 & 4 & 4 & 11.81 & 12.18 & 11.98 \\
\hline & 4 & 4 & 4 & 12.01 & 12.17 & 12.07 \\
\hline & 5 & 4 & 4 & 11.87 & 12.13 & 11.99 \\
\hline \multirow[t]{5}{*}{120} & 1 & 4 & 5 & 12.29 & 25.73 & 22.82 \\
\hline & 2 & 4 & 5 & 12.40 & 25.53 & 22.70 \\
\hline & 3 & 4 & 5 & 12.29 & 25.11 & 20.03 \\
\hline & 4 & 4 & 5 & 12.49 & 25.42 & 20.12 \\
\hline & 5 & 4 & 5 & 12.29 & 25.29 & 22.45 \\
\hline
\end{tabular}




\section{Sonuçlar}

Bu çalışmada 2-boyutlu palet yükleme problemi göz önüne alınarak kutuların en az sayıda palete yüklenmesi ve doluluk oranının en büyüklenmesi için bir Genetik Algoritma çözüm yaklaşımı uygulanmıştır. Elde edilen sonuçlara göre en az sayıda kutu sayısının elde edildiği ve son palet haricinde doluluk oranının belli seviyenin üzerinde olduğu görülmüştür. Çözüm süresinin uzun olması çözümün pratikliği açısından dezavantaj oluşturmakla beraber kutu sayısının en aza indirilmesi bir avantajdır.

Tablo 1'de görüldüğü üzere, 80, 100 ve 120 adet ürün kümesi için beşer test yapılmıştır. Bu testlerden elde edilen amaç fonksiyonu sonuçlarına göre minimum, maksimum ve ortalama değerler ve kullanılan palet sayısının minimum ve maksimum değerleri tabloda verilmiştir. 80 üründen oluşan veri kümesinde tüm ürünler 3 palete yüklenebilmiştir. 100 üründen oluşan veri kümesinde tüm ürünler bir test hariç 4 palete yüklenebilmiştir. Bu bir testte ürünlerin 3 palete yüklenebileceği sonucuna ulaşılmıştır. 120 üründen oluşan veri kümesinde ise tüm ürünler en az 4 en fazla ise 5 palete yüklenebilmiştir.

Tüm test sonuçları incelendiğinde ise kırılganlık ve müşteri siparişlerinin aynı palette olma kısıtlarını göz önüne alarak iyi sonuçlar elde edilmiştir.

Burada sunulan meta-sezgisel çözüm yaklaşımı, yazarların ileriki çalışmalarına temel oluşturmak ve Genetik algoritmaların palet yükleme problemlerindeki uygulamalarının temele indirgeyerek araştırmacıya/okuyucuya anlatmayı amaçlamaktadır. İleriki çalışmalarda, problemin çözüm süresinin optimizasyonu ve kısıtların geliştirilmesi üzerine çalışılacaktır.

\section{KAYNAKÇA}

Ahn, S., Park, C., \& Yoon, K. (2015b). An improved best-first branch and bound algorithm for the pallet-loading problem using a staircase structure. Expert Systems with Applications, 42(21), $7676-7683$.

Ahn, S., Yoon, K., \& Park, J. (2015a). A best-first branch and bound algorithm for the pallet-loading problem. International Journal of Production Research, 53(3), 835-849.

Alvarez-Valdés, R., Parreño, F., \& Tamarit, J. M. (2005). A branch-and-cut algorithm for the pallet loading problem. Computers \& Operations Research, 32(11), 3007-3029.

Beasley, J. E. (1985). An exact two-dimensional non-guillotine cutting tree search procedure. Operations Research, 33(1), 49-64.

Bhattacharya, S., Roy, R., \& Bhattacharya, S. (1998). An exact depth-first algorithm for the pallet loading problem. European Journal of Operational Research, 110(3), 610-625.

Birgin, E. G., Morabito, R., \& Nishihara, F. H. (2005). A note on an L-approach for solving the manufacturer's pallet loading problem. Journal of the Operational Research Society, 56(12), 1448-1451.

Bischoff, E. E., Janetz, F., \& Ratcliff, M. S. W. (1995). Loading pallets with non-identical items. European journal of operational research, 84(3), 681-692.

Chan, F. T., Bhagwat, R., Kumar, N., Tiwari, M. K., \& Lam, P. (2006). Development of a decision support system for air-cargo pallets loading problem: A case study. Expert Systems with Applications, 31(3), 472-485.

Chen, C. S., Sarin, S., \& Ram, B. (1991). The pallet packing problem for non-uniform box sizes. The International Journal of Production Research, 29(10), 1963-1968.

Dowsland, K. A. (1987a). An exact algorithm for the pallet loading problem. European Journal of Operational Research, 31(1), 78-84. 
Dowsland, K. A. (1987b). A combined data-base and algorithmic approach to the pallet-loading problem. Journal of the Operational Research Society, 38(4), 341-345.

Gencer, C. (2000) 2-Boyutlu Palet Yükleme Problemleri için Geliştirilen Karışık Tam Sayılı Doğrusal Programlama Modelinin Yeniden Düzenlenmesi. Niğde Üniversitesi Mühendislik Bilimleri Dergisi, 4(1), 11-17.

Jylänki, J. (2010). A thousand ways to pack the bin-a practical approach to two-dimensional rectangle bin packing. retrived from http://clb. demon. fi/files/RectangleBinPack. pdf.

Kır, S., \& Yazgan, H. R. (2019). A novel hierarchical approach for a heterogeneous 3D pallet loading problem subject to factual loading and delivery constraints. European Journal of Industrial Engineering, 13(5), 627-650.

Lau, H. C., Chan, T. M., Tsui, W. T., Ho, G. T., \& Choy, K. L. (2009). An Al approach for optimizing multipallet loading operations. Expert Systems with Applications, 36(3), 4296-4312.

Letchford, A. N., \& Amaral, A. (2001). Analysis of upper bounds for the pallet loading problem. European Journal of Operational Research, 132(3), 582-593.

Lins, L., Lins, S., \& Morabito, R. (2003). An L-approach for packing ( $\ell$, w)-rectangles into rectangular and L-shaped pieces. Journal of the Operational Research Society, 54(7), 777-789.

Martins, G. H., \& Dell, R. F. (2008). Solving the pallet loading problem. European Journal of Operational Research, 184(2), 429-440.

Mitchell, M. (1998). An introduction to genetic algorithms. MIT press.

Nelißen, J. (1995). How to use structural constraints to compute an upper bound for the pallet loading problem. European Journal of Operational Research, 84(3), 662-680.

Scheithauer, G. (2018). Pallet Loading. In Introduction to Cutting and Packing Optimization (pp. 279316). Springer, Cham.

Schuster, M., Bormann, R., Steidl, D., Reynolds-Haertle, S., \& Stilman, M. (2010, October). Stable stacking for the distributor's pallet packing problem. In 2010 IEEE/RSJ International Conference on Intelligent Robots and Systems (pp. 3646-3651). IEEE.

Sivanandam, S. N., \& Deepa, S. N. (2008). Genetic algorithms. In Introduction to genetic algorithms (pp. 15-37). Springer, Berlin, Heidelberg.

Song, X., Jones, D., Asgari, N., \& Pigden, T. (2019). Multi-objective vehicle routing and loading with time window constraints: a real-life application. Annals of Operations Research, 1-27.

Song, X., Jones, D., Asgari, N., \& Pigden, T. (2019). Multi-objective vehicle routing and loading with time window constraints: a real-life application. Annals of Operations Research, 1-27.

Tarnowski, A. G., Terno, J., \& Scheithauer, G. (1994). A polynomial time algorithm for the guillotine pallet loading problem. INFOR: Information Systems and Operational Research, 32(4), $275-$ 287.

Terno, J., Scheithauer, G., Sommerweiß, U., \& Riehme, J. (2000). An efficient approach for the multipallet loading problem. European Journal of Operational Research, 123(2), 372-381.

Terno, J., Scheithauer, G., Sommerweiß, U., \& Riehme, J. (2000). An efficient approach for the multipallet loading problem. European Journal of Operational Research, 123(2), 372-381.

Young-Gun, G., \& Kang, M. K. (2001). A fast algorithm for two-dimensional pallet loading problems of large size. European Journal of Operational Research, 134(1), 193-202. Topçu, Y.I., Kabak 
